\title{
Implications and Aspects of Lyme Neuroborreliosis
}

Authors:

Disclosure:

Received:

Accepted:

Keywords:

Citation:
Cody Riggle, ${ }^{1 *}$ Catherine A. Brissette ${ }^{2}$

1. University of North Dakota School of Medicine and Health Sciences, Grand Forks, North Dakota, USA

2. Department of Biomedical Sciences, University of North Dakota School of Medicine and Health Sciences, Grand Forks, North Dakota, USA

*Correspondence to catherine.brissette@und.edu

This work was associated with a National Institutes of Health $(\mathrm{NIH})$ grant: NIH P2O Centers of Biomedical Research Excellence (COBRE) P2OGM113123-01, HostPathogen Interactions. The authors have declared no conflicts of interest.

06.01 .21

09.02 .21

Borrelia, Lyme, neuroborreliosis.

EMJ Microbiol Infect Dis. 2021;2[1]:72-79.

\section{Abstract}

Lyme borreliosis or Lyme disease affects thousands of people globally each year, and, with nervous system involvement, this disease can lead to the development of Lyme neuroborreliosis (LNB). If not diagnosed and treated properly, LNB can lead to serious life-long health implications for affected patients. The clinical manifestations and treatment regimens are relatively well-studied, but much remains unknown about the disease's pathogenesis and epidemiology. In this review, the authors elucidate the knowns and unknowns of LNB.

\section{INTRODUCTION}

Lyme borreliosis, also known as Lyme disease, is an emerging infectious disease that has gained global attention. ${ }^{1}$ The name Lyme disease stems from Old Lyme, Connecticut, USA, where in the 1970s a cluster of oligoarthritis was observed in children who lived in rural environments. ${ }^{2,3}$ Subsequent investigations led to the true cause: spirochaetes of the genus Borrelia, which are transmitted via ticks of the genus Ixodes: ${ }^{2}$ Ixodes scapularis and Ixodes pacificus, found in the eastern and western parts of North America, respectively; and Ixodes ricinus and Ixodes persulcatus in Europe and Asia. The tick has a three-stage life cycle, which includes larval, nymph, and adult stages. ${ }^{2,4}$ Ticks in the larval stage will initially feed on a variety of animals that are reservoirs for spirochaetes, which include rodents,

birds, and other small vertebrates. The larvae will acquire the spirochaete from the infected host. ${ }^{2,4}$ After developing into the nymphal life-stage, the tick will often feed on similar species as the larval stage, thus transmitting the spirochaete to a new host, resulting in a cycle of infection (Figure 1). ${ }^{5}$ The nymphs may also feed on larger animals, including dead-end hosts, such as humans; nymphs are responsible for the majority of cases of Lyme disease in humans. ${ }^{1,2}$ Adult ticks primarily feed on larger animals such as deer, which are not considered competent hosts of Borrelia species but serve as a primary location for ticks to mate. ${ }^{6}$

Lyme borreliosis is the most common vectorborne disease in North America. ${ }^{1}$ Cases in the USA have increased from 10,000 annual cases in 1991 to $>25,000$ in 2014; ${ }^{1}$ however, the true number of infected individuals is thought to be under-reported by as much as 10-fold. 7,8 


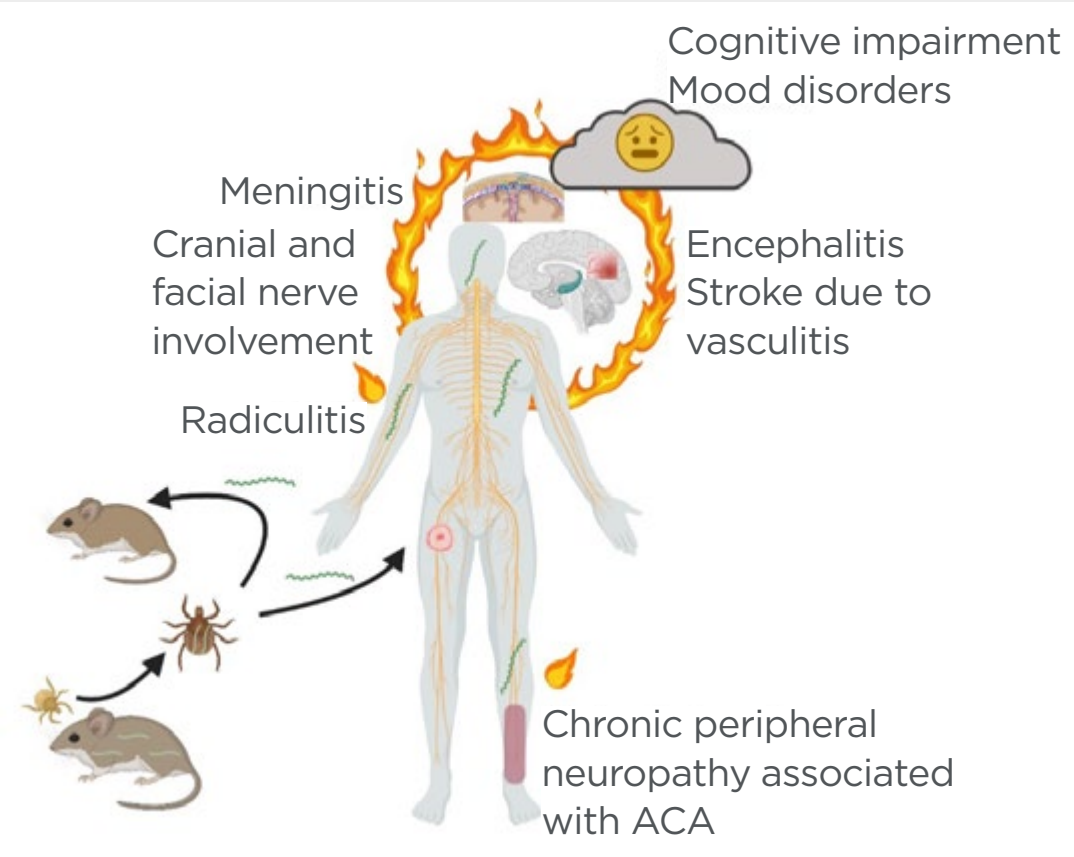

Figure 1: Borrelia life cycle and development of Lyme neuroborreliosis.

Larval ticks are uninfected as there is no trans-ovarial transmission of Lyme borreliae. Larval ticks feed on small vertebrates such as mice; if the tick feeds on an infected animal, it will acquire the spirochaete. Upon molting to the next life stage, the nymphal tick will again seek a blood meal, again from small animals or birds. If the tick feeds on an uninfected host, it will transmit the spirochaete to the reservoir host, thus maintaining the Lyme borreliae in nature. Nymphs will also feed on larger, dead-end hosts such as humans; indeed, the greatest risk of human infection with Lyme borreliae is through the bite of a nymphal tick. The spirochaetes disseminate from the initial bite site, where the characteristic erythema migrans rash occurs. Spirochaetes disseminate widely throughout the body and affect many tissues and organ systems including the joints, heart, and central and peripheral nervous systems. Nervous system involvement may include Lyme meningitis, radicular pain, and involvement of the cranial nerves, resulting in a temporary and partial paralysis of one side of the face (Bell's palsy). Less common but more serious manifestations include encephalitis or cerebral vasculitis. Long-term sequelae may occur, and many patients experience fatigue, mood changes, difficulty sleeping, and deficits in short-term memory or 'brain fog'. European patients with the late manifestation of acrodermatitis chronica atrophicans may experience chronic polyneuritis or neuropathy.

ACA: acrodermatitis chronica atrophicans.

Created with BioRender. ${ }^{5}$

In the USA, cases are most prevalent in the Midwest and Northeast. ${ }^{9}$ In Europe, Lyme borreliosis is most prevalent in Scandinavian countries and central Europe, with total estimates ranging from 65,000 to $>160,000$ per year.10,11 For example, in Germany there are approximately 30,000 cases annually, with some sources estimating the true number of annual cases to be 200,000.12 Lyme borreliosis in North America and Europe will likely continue to increase due to population growth, humans living in infected tick habitats, and climate change. Some studies predict that climate change will result in a $21 \%$ increase of Lyme borreliosis cases in the USA, as recorded temperature trends in the USA point to a probable increase of $2{ }^{\circ} \mathrm{C}$ by mid-century, resulting in a more stable and suitable environment for infected ticks. ${ }^{13}$

When the tick bites a human, it transmits spirochaetes with its saliva, resulting in a focal infection in the skin and distal systemic infections after 1-2 weeks. ${ }^{1,14,15}$ The spirochaetes responsible for Lyme borreliosis are collectively known as Borrelia burgdorferi sensu lato (Bbs/). Amongst 20 different species, there are three responsible for most disease seen in humans: ${ }^{2}$ in North America, Borrelia burgdorferi sensu stricto; in Europe, primarily Borrelia afzelii and Borrelia garinii. 2,7,14,16 The focal infection results in a visible, expanding skin rash known as erythema migrans in $60-80 \%$ of Lyme borreliosis cases in 
the USA; ${ }^{14,15}$ erythema migrans is also the most common manifestation of Lyme borreliosis in Europe. $^{2}$ Different genospecies of $\mathrm{Bbs} /$ cause differing signs and symptoms in their infected hosts.,2,17,18 For example, European patients may develop a late-stage skin disorder called acrodermatitis chronica atrophicans (ACA), which is not typically seen in North American patients. ${ }^{17,18}$ Other clinical manifestations of Lyme borreliosis arise from the effects of the disease on the heart, joints, and nervous system (Figure 1). $5,16,19$

\section{CLINICAL MANIFESTATIONS OF LYME NEUROBORRELIOSIS}

The course of Lyme borreliosis involves three stages: early localised, early disseminated, and late disseminated stages. ${ }^{2,14}$ The early localised stage is characterised by erythema migrans. The rash typically presents at the site of inoculation, 1-2 weeks after infection. ${ }^{2,14}$ The early disseminated stage usually starts 3-5 weeks after the initial tick bite and is characterised by the development of multiple secondary erythema migrans and cardiac and neurologic manifestations, typically facial nerve

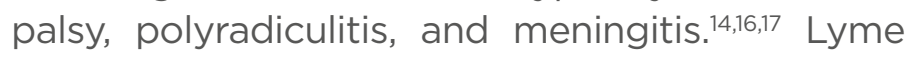
arthritis, ACA, and neurologic manifestations may occur during the late disseminated stage. $^{14}$ Neurologic manifestations, both early and late, can involve the central and peripheral nervous system ${ }^{19,20}$ and are collectively known as Lyme neuroborreliosis (LNB). ${ }^{12}$ Approximately 3-15\% of patients develop LNB. ${ }^{12,16,21}$ LNB may develop weeks to months after the host has been infected, and typical manifestations are peripheral, often bilateral, facial nerve palsy, polyradiculitis, and meningitis. Atypical presentations include myelitis or central nervous system (CNS) vasculitis. ${ }^{22}$

The first case of neuroborreliosis described in the literature involved a 58-year-old French male in 1922 who developed a large erythroderma after a tick bite.22,23 The man experienced bilateral radicular pain that eventually led to muscle weakness and atrophy. Analysis of his cerebrospinal fluid (CSF) revealed pleocytosis and elevated protein levels. A triad of meningitis, radiculoneuritis, and cranial neuritis encompasses the more common clinical manifestations of LNB. $^{22}$ Also, over half of the patients that experience radiculitis have symptoms that involve cranial nerves, more commonly the facial nerve, which can be unilaterally or bilaterally affected.12 Peripheral nervous system (PNS) involvement can also occur; this is particularly problematic as PNS manifestations can mimic other disease states. ${ }^{24}$ A recent study characterised a small cohort of patients with PNS involvement, documenting meningoradiculoneuritis with distal weakness and loss of sensation, axonal neuropathy with parasthesia and pain, and acute demyelinating neuropathy. ${ }^{24}$ As symptoms can be reversed with timely antibiotic therapy, it is crucial to be alert for PNS involvement.

Notably, there are regional differences for clinical manifestations between European and USA patients because of the different genospecies of $B$. burgdorferi causing infection. In Europe, the predominant species causing LNB include $B$. garinii and $B$. afzelii, while in the USA infection is predominately caused by $B$. burgdorferi sensu stricto. ${ }^{12}$ Adults in European countries with LNB caused by $B$. garinii typically experience a painful radiculitis with an asymmetric onset and lymphocytic meningoradiculitis (also known as Bannwarth syndrome), which lasts for weeks to months and is exacerbated at night-time. ${ }^{16,20}$ Segmental pain, often on the extremity where the tick bite occurred, appears first; this pain is intense and fails to respond to typical analgesics. ${ }^{25}$ Cranial nerve deficits often follow. ${ }^{25}$ Those infected with $B$. afzelii experience a broader range of symptoms that may include cognitive dysfunction and dizziness. ${ }^{12,20}$ Children and adolescents in Europe affected with LNB commonly present with lymphocytic meningitis. $^{12}$ The most common clinical manifestation of LNB in the USA is subacute aseptic meningitis with an onset within weeks to months after tick bite. ${ }^{16,19} \mathrm{Facial}$ palsy is also common. ${ }^{12}$ Children with LNB in the USA differ from their adult counterparts as the most common clinical manifestation is peripheral facial nerve palsy, rather than subacute aseptic meningitis. ${ }^{19,20}$ If a patient still has neurological manifestations for 6 months or longer, this is considered 'late Lyme neuroborreliosis'. ${ }^{12}$ Late LNB can occur 
months to years after being infected. Only a small proportion of patients with LNB go on to develop late LNB, characterised by chronic meningitis, progressive encephalitis, myelitis, or cerebral vasculitis. ${ }^{12}$ Polyneuropathy or polyneuritis as a late consequence of LNB can occur in association with ACA in European patients. ${ }^{25}$

\section{PATHOGENESIS OF LYME NEUROBORRELIOSIS}

Spirochaetes elicit an inflammatory response within the CNS including proinflammatory cytokines and chemokines and recruitment of immune cells. ${ }^{26-28}$ Unlike acute bacterial meningitis, patients with LNB present with a lymphocytic, rather than neutrophilic, pleocytosis in the CSF. ${ }^{29} \mathrm{~B}$ Iymphocytes are recruited, become activated, and mature into plasma cells. ${ }^{30}$ One diagnostic criterion of Lyme neuroborreliosis is the presence of Borrelia-specific antibodies in the CSF. ${ }^{31}$ The key role for inflammation in the pathogenesis of LNB is exemplified by studies involving dexamethasone treatment of rhesus macaques infected with $B$. burgdorferi. Animals treated with dexamethasone, a corticosteroid with anti-inflammatory properties, had significantly reduced levels of lymphocytic pleocytosis and immune mediators in the CSF. ${ }^{32}$ The dexamethasonetreated macaques also had no inflammatory lesions in the brain and spinal cord, no signs of focal neurodegeneration and demyelination in the spinal cord and peripheral nervous system, and a significant reduction in neuronal and glial cell apoptosis in the dorsal root ganglia. ${ }^{32}$ Markers of inflammation remained elevated in the infected macaques that were left untreated. There are several potential mechanisms for the neurological manifestations induced by $B b s /$ infection, including direct cytotoxicity, neurotoxic mediators, and production of autoantibodies. . $^{30,32,33}$ In addition to inducing an inflammatory response, spirochaetes bind to proteoglycans and/or galactocerebrosides on neuronal and glial cells in the CNS as well as Schwann cells of the PNS ${ }^{32}$ and can induce apoptosis. Bbsl do not produce or secrete toxins, but rather can induce the host's cells to secrete neurotoxic agents such as nitric oxide. ${ }^{30,32,33}$ Nitric oxide can then cause neuronal damage either directly, by inducing the production of pro-inflammatory cytokines, or by promoting vascular permeability. ${ }^{34}$ Another example is Bbs/-induced secretion of quinolinic acid; this neurotoxin is secreted by macrophages and causes neuronal death at high concentrations. ${ }^{30,33} \mathrm{Bbs} /$ infection can also induce the formation of auto-antibodies that attack components of the host's nervous system. ${ }^{30,33}$ While inflammation and a deleterious host immune response are clearly implicated in the pathogenesis of LNB, much is unknown, including bacterial factors contributing to neurotropism or neurotoxicity.

\section{DIAGNOSIS OF LYME NEUROBORRELIOSIS}

Indicators of LNB vary depending on the age and geographic location of the patient. Hence, the differential diagnosis for a patient with LNB can be quite broad. A presentation of cranial neuritis or subacute aseptic meningitis with a preceding erythema migrans rash makes a diagnosis of LNB more likely. ${ }^{35}$ Laboratory studies to confirm the possible diagnosis of LNB include methods that detect the presence of $\mathrm{Bbs} /$ and the immune response initiated against the bacteria. ${ }^{19}$ The direct detection of Bbs/, either in the CSF or other accessible fluids via culture or nucleic acid detection tests, currently holds low diagnostic value. ${ }^{19,35,36}$ Investigation of the CSF is the only way to make a definite diagnosis of LNB. CSF studies focus on three main parameters: lymphocytic pleocytosis, intrathecal antibody production, and protein content. 19,35,36 Lymphocytic pleocytosis with plasma cells, with an average cell count of 200 cells $/ \mathrm{mL}$, is an important cellular marker for the diagnosis of LNB as the presence of lymphocytes can help rule-out other neurological disorders. ${ }^{25,35}$ The CSF also usually exhibits an increased total protein content. ${ }^{25}$ Intrathecal IgM synthesis occurs in almost all patents with early manifestations, and is an important parameter but must be measured with caution because antibodies specific for Bbsl produced in the periphery can enter the CSF. 
Therefore, it is paramount that CSF antibody titres are measured in relation to the antibody titres from the serum from samples collected at the same time to determine the Borrelia-specific antibody index..$^{19,36}$ BloodCSF barrier function must be taken into account; a recommended calculation ${ }^{25}$ is:

specific IgG Ab CSF (units):spec.lgG antibody index $=\frac{\text { Ab serum (units) }}{\lg \text { concentration CSF }(\mathrm{mg} / \mathrm{mL}): \lg G}$ concentration serum $(\mathrm{mg} / \mathrm{mL})$

Serum studies are used to detect antibody production specific for Bbsl. In the USA, the Centers for Disease Control and Prevention (CDC) currently recommends a two-tier approach when testing serum from patients with suspected LNB. ${ }^{19}$ First, serum samples are screened by ELISA and positive or borderlinepositive results are followed with separate immunoblots for Bbs/-specific IgM and IgG. ${ }^{19}$ The two-tier approach has significant limitations, particularly in diagnosis of early disease, as there is a significant time lag between tick bite and specific antibody production. ${ }^{11}$ A cellular marker that shows promise for the detection of LNB is chemokine ligand 13 (CXCL13). ${ }^{37}$ CXCL13 is a chemoattractant for $B$ lymphocytes, and CXCL13 concentrations are elevated in the CSF during Bbs/ infections. ${ }^{19,36,38}$ Studies have also indicated that CXCL13 can be used as a cellular marker for active spirochaetal infection, as when patients with LNB are treated their CXCL13 concentrations drop significantly. However, CXCL13 is not specific for LNB and can be elevated in the CSF during other disease processes. The utility of CXCL13 during the diagnosis and management of LNB is still being determined but may be useful in monitoring treatment response. 19,37,39 Imaging studies such as MRI may be useful to rule out other neurological conditions. ${ }^{40,41}$ Electrophysiology studies, to measure compound muscle action potentials as well as abnormalities of F-waves or of conduction, can help differentiate between axonal and demyelinating neuropathies. ${ }^{24}$

\section{TREATMENT OF LYME NEUROBORRELIOSIS}

Treatment for LNB, with an oral or parenteral regimen, is dependent on the region where the patient was infected or lives and their disease pathology. If the patient is to be treated orally, doxycycline has the appropriate pharmacokinetics and pharmacodynamics. Doxycycline, when given daily in 200 mg doses, can reach concentrations in the CSF that are able to eliminate many $B b s /$ strains, ${ }^{42}$ because of doxycycline's high lipid solubility, which allows the drug to easily pass through the blood-brain barrier. ${ }^{43}$ It is recommended to treat the patient for 21 days with doxycycline in order to reach a steady-state equilibrium. Some studies have shown that giving patients a daily $400 \mathrm{mg}$ dose of doxycycline is more effective for treating LNB compared to the daily 200 mg dose, as effective CSF concentrations can be reached faster and the treatment duration can be shortened. ${ }^{44}$ The oral regimen with doxycycline for treating LNB is commonly used in European countries. ${ }^{31,42}$ Patients in the USA with LNB are typically treated with ceftriaxone parenterally for $10-14$ days. ${ }^{44}$ European researchers have demonstrated that $B$. burgdorferi sensu stricto, the spirochaete that causes the majority of LNB cases in the USA, is susceptible to oral doxycycline. ${ }^{43}$ In addition, doxycycline is found in similar concentrations in the blood of treated patients, whether it is given orally or intravenously. ${ }^{45}$ Despite the support for an oral treatment of LNB with doxycycline, the parenteral regimen may be preferred in cases, such as where there is evidence of parenchymal involvement. ${ }^{45}$ Lastly, while it is imperative to eradicate the spirochaetes with antibiotics, decreasing inflammation with nonsteroidal anti-inflammatory drugs ${ }^{46}$ may also be efficacious. Treatment recommendations for adult and paediatric patients at distinct stages of LNB are summarised in Table $1 .{ }^{47}$

\section{CONTROVERSIES RELATED TO LYME NEUROBORRELIOSIS}

The term 'chronic' can refer to an illness persisting for a long time. ${ }^{48}$ In terms of Lyme borreliosis, the term has been applied both to late-stage manifestations of the disease (e.g., ACA), ${ }^{18}$ as well as a catch-all term for patients suffering from a multi-system dysfunction with prolonged fatigue, pain, and neurological issues. ${ }^{49}$ Chronic Lyme disease (CLD) is a controversial diagnosis that can encompass a variety of patient populations. 
Table 1: Treatment doses for Lyme disease and Lyme neuroborreliosis.

\begin{tabular}{|c|c|c|c|c|c|}
\hline & LD & Early LNB & Facial palsy* & $\begin{array}{l}\text { Meningitis/ } \\
\text { radiculoneuritis* }\end{array}$ & Late LNB \\
\hline \multicolumn{6}{|l|}{ Adult doses } \\
\hline Doxycycline & $\begin{array}{l}200 \mathrm{mg} \text { daily for } \\
10-14 \text { days }\end{array}$ & $\begin{array}{l}200 \mathrm{mg} \text { daily for } \\
14-28 \text { days }\end{array}$ & $\begin{array}{l}100 \mathrm{mg} \text { twice daily } \\
\text { for } 14-21 \text { days }\end{array}$ & $\begin{array}{l}200 \text { mg daily } \\
\text { divided into 1-2 } \\
\text { doses for 14-21 } \\
\text { days }\end{array}$ & $\begin{array}{l}200 \text { mg daily for } \\
28 \text { days }\end{array}$ \\
\hline Ceftriaxone & $\begin{array}{l}2 \text { g daily for } 14 \\
\text { days }\end{array}$ & $\begin{array}{l}2 \text { g daily for } 14-28 \\
\text { days }\end{array}$ & NR & $\begin{array}{l}2 \mathrm{~g} \text { intravenously } \\
\text { once daily for } \\
\text { 14-21 days }\end{array}$ & $\begin{array}{l}2 \text { g daily for } 14-28 \\
\text { days }\end{array}$ \\
\hline \multicolumn{6}{|c|}{ Paediatric doses } \\
\hline Doxycycline & $\begin{array}{l}\text { Two doses of } 4.4 \\
\mathrm{mg} / \mathrm{kg} \text { for } 10-14 \\
\text { days (max. of } 100 \\
\text { mg/dose) }\end{array}$ & $\begin{array}{l}\text { Two doses of } 4.4 \\
\mathrm{mg} / \mathrm{kg} \text { for } 14-28 \\
\text { days (max. of } 100 \\
\text { mg/dose) }\end{array}$ & $\begin{array}{l}4.4 \mathrm{mg} / \mathrm{kg} \text { per } \\
\text { day orally, divided } \\
\text { into } 1-2 \text { doses for } \\
14-21 \text { days (max. } \\
100 \text { mg/dose) }\end{array}$ & $\begin{array}{l}4.4 \mathrm{mg} / \mathrm{kg} \text { per } \\
\text { day orally, divided } \\
\text { into } 1-2 \text { doses for } \\
14-21 \text { days (max. } \\
100 \mathrm{mg} / \text { dose) }\end{array}$ & $\begin{array}{l}\text { Two doses of } 4.4 \\
\mathrm{mg} / \mathrm{kg} \text { for } 28 \text { days } \\
\text { (max. } 100 \mathrm{mg} / \\
\text { dose) }\end{array}$ \\
\hline Ceftriaxone & $\begin{array}{l}50-100 \mathrm{mg} / \mathrm{kg} \text { for } \\
14 \text { days (max. } 2 \mathrm{~g} / \\
\text { dose) }\end{array}$ & $\begin{array}{l}50-100 \mathrm{mg} / \mathrm{kg} \text { for } \\
14-28 \text { days (max. } \\
2 \mathrm{~g} / \text { dose) }\end{array}$ & NR & $\begin{array}{l}\text { 50-75 mg/kg } \\
\text { intravenously } \\
\text { once daily for } \\
\text { 14-21 days (max. } 2 \\
\text { g/dose) }\end{array}$ & $\begin{array}{l}50-100 \mathrm{mg} / \mathrm{kg} \text { for } \\
14-28 \text { days (max. } \\
2 \mathrm{~g} / \text { dose) }\end{array}$ \\
\hline
\end{tabular}

${ }^{*}$ Centers for Disease Control and Prevention (CDC) Neurologic Lyme recommendations. ${ }^{47}$

LD: Lyme disease; LNB: Lyme neuroborreliosis; max.: maximum; NR: not recommended.

Adapted from Stanek and Strle. ${ }^{17}$

These patient populations include patients diagnosed with post-treatment Lyme disease syndrome (PTLDS), patients experiencing prolonged objective symptoms of Lyme disease, and patients with unexplained clinical manifestations that have not previously been diagnosed with Lyme borreliosis. ${ }^{50-53}$ The Infectious Diseases Society of America (IDSA) provides a working definition for PTLDS as symptoms in patients who have been previously appropriately treated for Lyme borreliosis and remain symptomatic for at least 6 months, with subjective symptoms including fatigue, pain, and cognitive issues that are severe enough to interfere with work, school, and life. ${ }^{51,54,55}$ The International Lyme and Associated Diseases Society (ILADS) has recently provided a definition for CLD, but the definition is broad and still creates challenges for excluding CLD from other disorders or syndromes. ${ }^{52}$ ILADS defines CLD as a multisystem illness with a wide range of symptoms present for a minimum of 6 months, either intermittent or continuous, and includes subcategories: untreated CLD and previously treated CLD. Many of the patients diagnosed with CLD experience the following symptoms: fatigue, myalgias, arthralgias, headaches, and subjective cognitive dysfunction. ${ }^{50,51}$ Notably, many of those symptoms overlap with the experiences of patients with PTLDS. Some patients referred for CLD are found to be experiencing an unrelated neurologic, psychiatric, or rheumatologic condition. ${ }^{50,51}$ The picture is complicated by patients with a previous Lyme borreliosis diagnosis that experience residual symptoms for months after treatment. As with other infections, some patients will commonly experience prolonged fatigue after their infection resolves. Prolonged 
fatigue, along with symptoms such as chronic pain, are relatively frequent findings, even in the general population. ${ }^{50}$ Differentiating between these symptoms is a dilemma for clinicians, especially when deciding whether to treat with long-term antibiotic therapy. Several studies have concluded that further antibiotic use for patients experiencing prolonged Lyme borreliosis symptoms is not beneficial and may be harmful to the patient. ${ }^{50,51,53}$ Adverse events that have occurred include catheterassociated venous thromboembolism, catheter-associated bacteraemia, and allergic reactions. ${ }^{53,56} \mathrm{~A}$ clinician will ideally examine the patient with a holistic assessment, being alert to other diagnoses while remaining sensitive to the patient's symptoms and concerns. This is particularly important as many of these patients feel ignored or abandoned by the medical establishment and may turn to alternative sources of information. Unfortunately, selfdiagnosis of CLD has contributed to the death of a patient. ${ }^{57}$ It is imperative that clinicians work to build a sense of trust with the patient to combat the all-too-common dissatisfaction with the medical community from patients with CLD symptoms. ${ }^{49,51-53}$

\section{CONCLUSION}

Lyme borreliosis is caused by a spirochaetal infection, which can involve the nervous system. With cases increasing significantly on a global scale, the importance of continued research into LNB is evident. Future research into LNB should focus on aspects of borrelial pathogenesis and the epidemiology of the disease, as well as on the development of more effective diagnostic tools for this serious disease.

\section{References}

1. Applegren ND, Kraus CK. Lyme disease: emergency department considerations. J Emerg Med. 2017;52:815-24.

2. Radolf JD et al. Lyme disease in humans. Curr Issues Mol Biol. 2020;42:333-84.

3. Barbour AG, Benach JL. Discovery of the Lyme disease agent. mBio. 2019;10(5):e02166-19.

4. Radolf JD et al. Of ticks, mice and men: understanding the dualhost lifestyle of Lyme disease spirochaetes. Nat Rev Microbiol. 2012;10:87-99.

5. BioRender. BioRender. 2021. Available at: https://biorender.com/. 2021. Last accessed: 25 February 2021.

6. Telford SR $3^{\text {rd }}$ et al. Incompetence of deer as reservoirs of the Lyme disease spirochete. Am J Trop Med Hyg. 1988;39(1):105-9.

7. Hinckley AF et al. Lyme disease testing by large commercial laboratories in the United States. Clin Infect Dis. 2014;59(5):676-81.

8. Nelson CA et al. Incidence of clinician-diagnosed Lyme disease, United States, 2005-2010. Emerg Infect Dis. 2015;21(9):1625-31.

9. Centers for Disease Control and Prevention. Lyme disease maps: most recent year. 2018. Available at: https:// www.cdc.gov/lyme/datasurveillance/ maps-recent.html. Last accessed: 5 January 2021.

10. Rizzoli A et al. Lyme borreliosis in Europe. Euro Surveill. 2011;16(27):19906.

11. Sykes RA, Makiello P. An estimate of Lyme borreliosis incidence in Western Europe. J Public Health (Oxf). 2017;39(1):74-81.

12. Koedel $U$ et al. Lyme neuroborreliosis-epidemiology, diagnosis and management. Nat Rev Neurol. 2015;11:446-56.

13. Dumic I, Severnini E. "Ticking bomb": the impact of climate change on the incidence of Lyme disease. Can J Infect Dis Med Microbiol. 2018;2018:5719091.

14. Steere AC et al. Lyme borreliosis. Nat Rev Dis Primers. 2016;2:1-18.

15. Younger DS. Epidemiology of Lyme neuroborreliosis. Neurol Clin 2016;34:875-86.

16. Hildenbrand $P$ et al. Lyme neuroborreliosis: manifestations of a rapidly emerging zoonosis. Am J Neuroradiol. 2009;30:1079-87.

17. Stanek G, Strle F. Lyme borreliosis-from tick bite to diagnosis and treatment. FEMS Microbiol Rev. 2018;42:233-58.

18. Gade A et al. Acrodermatitis chronica atrophicans. 2020. Available at: https://www.ncbi.nlm.nih.gov/books/ NBK563289/. Last accessed: 25 February 2021.

19. Marques AR. Lyme neuroborreliosis. Continuum (Minneap Minn). 2015;21(6 Neuroinfectious Disease):1729-4.

20. Garcia-Monco JC, Benach JL. Lyme neuroborreliosis: clinical outcomes, controversy, pathogenesis, and polymicrobial Infections. Ann Neurol. 2019;85:21-31.

21. Tuerlinckx D, Glupczynski Y. Lyme neuroborreliosis in children. Expert Rev Anti Infect Ther. 2010;8:455-63.

22. Halperin JJ. Nervous system Lyme disease. Handb Clin Neurol. 2014;121:1473-83.

23. Henderson D, Wong TC. "Erythroderma", Usatine RP et al. (eds.), The Color Atlas and Synopsis of Family Medicine (2019), 3rd edition, New York: McGraw-Hill, pp.3e(162).

24. Kaminsky AL et al. Confirmed cases of neuroborreliosis with involvement of peripheral nervous system. Medicine. 2020;99(40):e21986

25. Rauer $\mathrm{S}$ et al. Guidelines for diagnosis and treatment in neurology- Lyme neuroborreliosis. Ger Med Sci. 2020;18:Doc03.

26. Ramesh $\mathrm{G}$ et al. Interaction of the Lyme disease spirochete Borrelia burgdorferi with brain parenchyma elicits inflammatory mediators from glial cells as well as glial and neuronal apoptosis. Am J Pathol. 2008;173(5):1415-27.

27. Jacobsen $\mathrm{M}$ et al. Clonal accumulation of activated CD8+ T cells in the central nervous system during the early phase of neuroborreliosis. J Infect Dis. 2003;187(6):963-73.

28. Lunemann JD et al. Cerebrospinal fluid-infiltrating CD4+ T cells recognize Borrelia burgdorferi lysineenriched protein domains and central nervous system autoantigens in early 
Lyme encephalitis. Infect Immun. 2007;75(1):243-51.

29. Pachner AR et al. Central nervous system manifestations of Lyme disease. Arch Neurol. 1989;46(7):790-5.

30. Rupprecht TA et al. The pathogenesis of Lyme neuroborreliosis: from infection to inflammation. Mol Med. 2008;14:205-12.

31. Jaulhac B et al. Lyme borreliosis and other tick-borne diseases. Guidelines from the French scientific societies (II). Biological diagnosis, treatment, persistent symptoms after documented or suspected Lyme borreliosis. Med Mal Infect. 2019;49(5):335-46.

32. Ramesh $\mathrm{G}$ et al. Inflammation in the pathogenesis of Lyme neuroborreliosis. Am J Pathol. 2015;185:1344-60.

33. Nasierowski T et al. Psychosis in Borrelia burgdorferi infection - part I: epidemiology, pathogenesis, diagnosis and treatment of neuroborreliosis. Psychiatr Pol. 2019:53:629-40.

34. Garcia-Monco JC, Benach JL. Mechanism of injury in Lyme neuroborreliosis. Semin Neurol. 1997;17:57-62.

35. Stiernstedt $\mathrm{G}$ et al. Clinical manifestations and diagnosis of neuroborreliosis. Ann N Y Acad Sci. 1988;539:46-55.

36. Halperin JJ. Diagnosis and management of Lyme neuroborreliosis. Expert Rev Anti Infect Ther. 2018;16:5-11.

37. Gudowska-Sawczuk M, Mroczko B Chemokine ligand 13 (CXCL13) in neuroborreliosis and neurosyphilis as selected spirochetal neurological diseases: a review of its diagnostic significance. Int J Mol Sci. 2020;21(8):2927.
38. Hagberg L. Diagnosis of Lyme neuroborreliosis. Infect Dis (Lond) 2019;51:864-65.

39. Knudtzen FC et al. The predictive value of CXCL13 in suspected Lyme neuroborreliosis: a retrospective crosssectional study. Eur J Clin Microbiol Infect Dis. 2020;39(8):1461-70.

40. Orbaek $M$ et al. CT and MR neuroimaging findings in patients with Lyme neuroborreliosis: a national prospective cohort study. J Neurol Sci. 2020;419:117176.

41. Garkowski A et al. Imaging of Lyme neuroborreliosis: a pictorial review. Open Forum Infect Dis. 2020;7(10):ofaa370

42. Halperin JJ et al. Practice parameter treatment of nervous system Lyme disease (an evidence-based review): report of the Quality Standards Subcommittee of the American Academy of Neurology. Neurology. 2007;69:91-102.

43. Cunha BA. Minocycline versus doxycycline in the treatment of Lyme neuroborreliosis. Clin Infect Dis. 2000;30:237-8.

44. Lantos PM et al. Clinical practice guidelines by the Infectious Diseases Society of America (IDSA), American Academy of Neurology (AAN), and American College of Rheumatology (ACR): 2020 guidelines for the prevention, diagnosis, and treatment of Lyme disease. Arthritis Rheumatol. 2021;73(1):12-20

45. Wormser GP, Halperin JJ. Oral doxycycline for neuroborreliosis. Lancet Neurol. 2008:7:655-6.

46. Pachner AR. The therapy of Lyme neuroborreliosis. Curr Treat Options Neurol. 2005;7:167-170.

47. Centers for Disease Control and Prevention. Lyme treatment: Neurologic Lyme. 2020. Available at: https://www.cdc gov/lyme/treatment/NeurologicLyme. html. Last accessed: 25 February 2021.
48. Oxford English Dictionary. Chronic, adj. Available at: https://www.oed. com/view/Entry/32570?redirectedFrom=chronic\#eid. Last accessed: 5 January 2021

49. Bamm VV et al. Lyme disease frontiers: reconciling Borrelia biology and clinical conundrums. Pathogens. 2019;8(4):299.

50. Marques A. Chronic Lyme disease: a review. Infect Dis Clin North Am. 2008;22:341-60.

51. Lantos PM. Chronic Lyme disease: the controversies and the science. Expert Rev Anti Infect Ther. 2011;9:787-97.

52. Shor S et al. Chronic Lyme disease: an evidence-based definition by the ILADS Working Group. Antibiotics (Basel). 2019;8:269.

53. Lantos PM. Chronic Lyme disease. Infect Dis Clin North Am. 2015;29:325-40.

54. Wormser GP et al. The clinical assessment, treatment, and prevention of Lyme disease, human granulocytic anaplasmosis, and babesiosis: clinical practice guidelines by the Infectious Diseases Society of America. Clin Infect Dis. 2006;43(9):1089-134.

55. Aucott JN et al. Development of a foundation for a case definition of post-treatment Lyme disease syndrome. Int J Infect Dis. 2013;17(6):e443-9.

56. Kobayashi T et al. Misdiagnosis of Lyme disease with unnecessary antimicrobial treatment characterizes patients referred to an academic infectious diseases clinic. Open Forum Infect Dis. 2019;6(7):ofz299.

57. Strivoza Z et al. Internet-based selfdiagnosis of Lyme disease caused death in a young woman with systemic lupus erythematosus. Joint Bone Spine. 2019;86(5):650-1. 